Article

\title{
In-Flight Casinos, Is It Really a Nonsensical Idea? An Exploratory Approach Using Different Choice Experiments
}

\author{
Jinsoo Hwang ${ }^{1}$, Seong Ok Lyu ${ }^{2, *(1)}$ and Sun-Bai Cho ${ }^{3}$ \\ 1 The College of Hospitality and Tourism Management, Sejong University, 98 Gunja-dong, Gwanjin-gu, \\ Seoul 143-747, Korea; jhwang@sejong.ac.kr \\ 2 School of Global Sport Studies, Korea University, 2511 Sejong-ro, Sejong 30019, Korea \\ 3 The Department of Hotel Management, Cheongju University, Cheongju, Chungcheongbuk-do 28503, Korea; \\ johnsp@cju.ac.kr \\ * Correspondence: watchdog88@korea.ac.kr
}

Received: 16 April 2019; Accepted: 25 May 2019; Published: 29 May 2019

check for updates

\begin{abstract}
Most airlines make various efforts to enhance their customers' levels of in-flight satisfaction while offering alternative services and entertainment. As an innovative service item, some international airlines plan in-flight casino facilities to relieve their customers' boredom and fatigue emanating from tedious long flights. Using a study sample of casino visitors in Korea, we intend to better understand how potential airline passengers show their willingness to pay for the hypothetical in-flight casino services. We also employ multiple choice experimental techniques to examine preference heterogeneity embedded in the sampled population. Based on study results, several management strategies are discussed for offering tailored in-flight entertainment services to targeted market segments.
\end{abstract}

Keywords: in-flight casino; choice experiment; service quality; willingness to pay

\section{Introduction}

First-class is well known for a larger and more comfortable space and the highest standard of service during a flight, so it is called 'the most luxurious form of travel' in the airline industry [1]. First-class has been an important part of making profits for airlines [2], but in the last few years, many airlines (e.g., American Airlines, Qantas Airways, Singapore Airlines) have been trying to decrease the number of first-class seats or eliminate first-class seats to make greater profits [3]. The airline industry in Korea is in a similar circumstance. Asiana Airlines, the second largest airline company in Korea, announced its plan to cut back on the number of first-class seats due to them being less profitable [4]. In addition, the growth of the low-cost airline industry has led to a change in the number of first-class seats. According to the Korea Herald [5], low-cost airlines accounted for about 50 percent of domestic passengers for the first time in 2014. Such a phenomenon puts pressure on full-service carriers to implement a new type of management system.

This study intends to suggest a new business model for such a new type of management system, focusing on in-flight casinos as a major breakthrough. It has been proven that a casino has a key role in making a profit while traveling. Particularly in the case of a cruise trip, passengers spend several hours on the cruise ship, so they tend to play casino games in order to relieve the boredom of long trips. For instance, Ji and Mazzarella [6] argued that on-board casino operations help to enhance cruise line revenue. Similarly, Ng and Yip [7] also suggested that a ship's casino is very popular and an important source of revenue. These studies show that an in-flight casino is a new service that can give airlines such high profitability. In particular, such high profitability could contribute to the 
technological development of environmental-friendly management methods, which are costly [8]. In addition, similar to a cruise trip, passengers would feel cramped and uncomfortable in a confined space during long-haul flights. Therefore, if the airlines provide casino games for their passengers, it would play an important role in relieving the boredom and fatigue of tedious flights, which would enhance passenger satisfaction with air travel.

It is widely known that service quality directly affects customer satisfaction, so it is considered a crucial factor of enhancing business profits [9-13]. For this reason, many academics and practitioners have focused on identifying and improving service quality in diverse fields. Unfortunately, despite the potential for a successful business of an in-flight casino, no study to date has examined service quality of an in-flight casino. To fill this gap, this study aimed to examine the most suitable service quality for operating an in-flight casino using choice modeling techniques, so the findings of this study could help airlines in designing and launching an in-flight casino.

\section{Literature Review}

\subsection{The Economic Effect of the Casino Industry}

It is widely known that the casino industry is good for the national economy. Official statistics support this statement. For instance, according to American Gaming Association (AGA) [14], the total gross gaming revenue of U.S. casinos amounted to about US $\$ 40.28$ billion in 2017 , indicating an increase of $3.4 \%$ over 2016. In addition, AGA also reported that there are 460 commercial casinos, which generated approximately $\$ 9.23$ billion in direct gaming tax revenue in 2017. As for Macao, the situation is similar. Macao is considered the world's biggest gaming center, and its gaming industry has played a significant role in the economy. For example, casinos generated about US $\$ 37.6$ billion in 2018 [15]. In particular, the role of casinos is important because taxes from casinos account for $80 \%$ of the Macau government's total revenue [15]. The importance of the casino industry is no exception for Korea. The operating system of a casino in Korea is different to those in other countries as a casino's entrance is classified according to nationality. The total number of casinos in Korea is 17. Among them, only one casino, Kangwon Land Casino, is available for Koreans and is located in Jeongson-Gun Kwangwon Province, while others are operating for foreign nationals. Kangwon Land Casino was designed to contribute to improving the regional economy in 2001, making about US\$400 million with 900,000 visitors. Currently, the casino generates about US $\$ 2.7$ billion with five million visitors in 2017 [16]. These statistics from each country indicate the casino industry is an economically viable industry and plays a crucial role in the development of national and regional economies.

\subsection{Casino Service Quality}

It is widely accepted that service quality is regarded as an important factor in enhancing customer satisfaction and behavioral intention, so academics and practitioners have taken great effort to find ways to improve service quality in diverse fields [17-20]. The importance of service quality is no exception to the casino industry, so previous empirical studies have done a lot of work to identify the important role of service quality factors in the casino industry [21-28].

Table 1 summarizes the research on service quality in the casino industry. For instance, Lam et al. [25] applied servicescape, consisting of five dimensions: ambience, navigation, seating comfort, interior décor, and cleanliness to the casino industry in order to identify how the physical environment affects customer satisfaction as well as behavioral intentions. They collected data from 513 casino customers in Macau and found that servicescape, except for ambience and cleanliness, has a positive influence on customer satisfaction, which in turn positively affects behavioral intentions. Based on the results of the data analysis, they suggested that casinos are required to focus more on navigation (e.g., sight lines, aisle width, signs/directions), seating comfort (seat back, elbow room, distance from table), and interior décor (e.g., background colors, wall treatment design, and floor treatment design). 
Mayer and Johnson [27] collected data from 185 casino customers in order to examine the important factor of casino atmospherics and suggested that the following elements of casino atmospherics are considered critical casino atmospherics: enjoyment, décor/color, floor layout, theme, employee uniforms, ceiling heights, and noise level. Lio and Rody [26] explored the important role of the service environment in the casino industry using data collected from 158 Chinese gamblers in Macau. They found that seating comfort, cleanliness, interior decoration, and gaming facilitators are positively associated with overall quality, which in turn affect emotions. Wong and Fong [28] first proposed CASERV (known as casino service quality), which consists of (1) game service, (2) service environment, (3) service delivery, and (4) food service. They collected data from 238 casino customers and found that four sub-dimensions of CASERV have high levels of convergent validity, discriminant validity, and internal consistency. Carrying the previous study a step further, Hwang and Han [21] explored the important role of CASERV affecting outcome variables using empirical data collected from 228 casino customers in the United States. They found that CASERV, except for food service, has a positive impact on brand prestige, which in turn positively affects social value, brand preference, and revisit intentions, suggesting that casino managers need to provide (1) many different table games and slot machines, (2) a pleasant environment to play casino games, and (3) high quality of employee service.

Jeon and Hyun [23] developed a theoretical model in order to identify the effects of casino service quality on casino customer satisfaction using 1500 baby boomers. Their results were similar to CARSERV. For instance, they found the following five dimensions of casino service quality: slot machines, table games, non-gaming attributes (e.g., employee service, hotel rooms, and restaurant), winning perception, and promotions and benefits. In addition, they showed that such casino service qualities positively affect casino customer satisfaction. Jeon et al. [24] used the SERVQUAL model in order to find the antecedents and consequences of casino players' satisfaction. They collected data from 383 casino players and found that four dimensions of SERVQUAL (tangibility, responsiveness, assurance, and empathy) were found to be important predictors of casino players' satisfaction. In addition, they suggested that casino players' satisfaction plays a significant role in the formation of brand affect and game spending. Consequently, they stressed that casinos need to focus more on tangible parts (e.g., diverse gaming equipment, comfortable game areas, and attractive physical surroundings) and systematic training programs for enhancing responsiveness, assurance, and empathy.

Table 1. Summary of casino service quality.

\begin{tabular}{|c|c|c|}
\hline Authors (Year) & Casino Service Quality & Outcome Variables \\
\hline Lam et al. (2011) [25] & $\begin{array}{l}\text { Ambience, Navigation, Seating comfort, Interior } \\
\text { décor, Cleanliness }\end{array}$ & $\begin{array}{c}\text { Customer satisfaction, Behavioral } \\
\text { intentions }\end{array}$ \\
\hline Mayer and Johnson (2012) [27] & $\begin{array}{l}\text { Enjoyment, Décor/color, Floor layout, Theme, } \\
\text { Employee uniforms, Ceiling heights, Noise level }\end{array}$ & \\
\hline Lio and Rody (2012) [26] & $\begin{array}{l}\text { Seating comfort, Cleanliness, Interior Decoration, } \\
\text { Gambling facilitators }\end{array}$ & Overall quality, Emotions \\
\hline Wong and Fong (2012) [28] & $\begin{array}{l}\text { Game service, Service environment, Service } \\
\text { delivery, Food service }\end{array}$ & \\
\hline Jeon and Hyun (2013) [23] & $\begin{array}{l}\text { Slot machines, Table games, Non-gaming attributes, } \\
\text { Winning perception, Promotions and benefits }\end{array}$ & Satisfaction \\
\hline Jeon et al. (2013) [24] & Tangibility, Responsiveness, Assurance, Empathy & Brand affect, Game spending \\
\hline Hwang and Han (2016) [21] & $\begin{array}{l}\text { Game service, Service environment, Service } \\
\text { delivery }\end{array}$ & Brand prestige \\
\hline Hwang et al. (2016) [22] & $\begin{array}{l}\text { Perceived dealer attribute-expertise, likeability, } \\
\text { and customer orientation }\end{array}$ & $\begin{array}{c}\text { Rapport between players and } \\
\text { dealers }\end{array}$ \\
\hline
\end{tabular}


More recently, Hwang et al. [22] tried to investigate the important role of casino dealers during the table games using 224 casino table game players. They suggested that three types of perceived dealer attribute (i.e., expertise, likeability, and customer orientation) help to enhance rapport between players and dealers. In addition, the same authors argued that rapport between players and dealers plays an important role in the formation of satisfaction, commitment, and customer citizenship behavior (i.e., feedback, advocacy, helping, and tolerance), suggesting that it is necessary to provide a well-developed training program for casino dealers in order to form favorable relationships with casino players.

In summary, previous studies have proposed the following eight sub-dimensions of service quality including game duration, casino capacity, internal environment, number of games, service quality, comps, instruction, and entrance fee either individually or collectively in the casino industry [21,23,27]. In particular, such service qualities aid to form customer satisfaction and behavioral intentions, so they have a direct impact on casino profits [22,28].

\subsection{Choice Experiment}

Across many disciplines including transportation, environmental studies, marketing, as well as tourism and hospitality, the choice experiment (hereafter $\mathrm{CE}$ ) has been popularly utilized to be better aware of consumers' innate preferences for particular products and services. This microeconomic technique is known to be advantageous in assessing consumer surplus or demand for hypothetical goods and services that are not available in real markets [29,30]. Following the stated preference (hereafter SP) theory, which involves requesting respondents to choose a favorite option from a range of alternatives, the CE is acknowledged as offering a deeper insight into consumers' willingness to pay for hypothetical products than the contingent valuation method (CVM), the most typical SP-based economic valuation technique [31]. This advantage is attributed to the CE's basis assuming respondents' complicated trade-offs among multiple attributes [32].

Apart from the theory of utility maximization postulating that regular consumers with budget constraints choose optimal products that are believed to provide the greatest amount of utility, the $\mathrm{CE}$ is based on another important assumption of random utility theory. According to this theory, utility comprises two different aspects: Observable and unobservable. The utility of an individual $i$ choosing a hypothetical product $j$ can be expressed as $U_{i j}=V_{i j}+\epsilon_{i j}=\beta X_{i j}+\epsilon_{i j}$, where $V_{i j}$ represents the observable element; $\epsilon_{i j}$, the unobserved random error component; $X_{i j}$, a combination of different levels of attributes; $\beta$, the vector of parameter estimates. The probability of choosing a product $j$ can be shown as, $P_{i j}=\frac{\exp \left(\beta X_{i j}\right)}{\sum_{k \in C_{i}} \exp \left(\beta X_{i k}\right)}$, which can be represented using the conditional logit model proposed by McFadden [33]. This traditional conditional logit algorithm largely violates the restrictive assumption of the independence of irrelevant alternative (hereafter IIA) denoting that "the ratio of the choice probabilities of any two alternatives is entirely unaffected by the systematic utilities of any other alternatives" [34].

In order to evade the IIA requirement, previous studies have recruited the random parameter logit (hereafter RPL) model while incorporating the unobservable respondents' preference heterogeneity in the deterministic element of the utility function through handling parameter estimates of different attributes as random variables [35]. This modeling approach is accordingly useful in examining how parameter estimates are distributed, assumed by researchers to have a particular distribution pattern, which reflects the presence of respondents' preference heterogeneity [36]. Since each random parameter is not known, the unconditional probability can be integrated over all values of $\beta$ using the maximum simulated likelihood estimation (hereafter MSLE) as $P_{i j}=\int\left(\frac{\exp \left(\beta X_{i j}\right)}{\sum_{k} \exp \left(\beta X_{i k}\right)}\right) f(\beta \mid \theta) d \beta$ for a given value of $\theta$. In order to better view respondents' heterogeneous preference structures, a set of socio-demographic and attitudinal features are often included into the indirect utility functions [30]. Among different MSLE methods, the Halton draws has been most popularly used for stable parameterization [37].

The application of the latent class (hereafter LC) model is known to be another effective scheme for eschewing the restrictive IIA property. This model enables researchers to recognize how many 
heterogeneous groups of respondents (i.e., segments) characterized by relatively homogeneous preference structures are present in the sampled population [38]. The infinite number of segments can be endogenously determined through class membership functions, which are dependent upon respondents' socio-demographic and attitudinal features [39]. Given that a consumer $i$ belongs to class $s$, the probability can be expressed as $P_{i j \mid s}=\frac{\exp \left(\beta_{s} X_{i j}\right)}{\sum_{k \in C_{i}} \exp \left(\beta_{s} X_{i k}\right)}$, where $\beta_{s}$ represents segment-specific parameter estimates. Since the addition of socio-demographic and attitudinal factors affects the class membership function, the probability that the respondents $i$ becomes a member of class $s$ can be presented as $P_{i \mid s}=\frac{\exp \left(\lambda_{s} Z_{i}\right)}{\sum_{s=1}^{S} \exp \left(\lambda_{s} Z_{i}\right)}$, where $Z_{i}$ represents a vector of personal characteristics; $\lambda_{s}$ denotes a vector of parameter estimates. Through combining these equations, the probability that the consumer $i$ belongs to group $s$ and purchases the product $j$ can be expressed as $P_{i j \mid s}=\sum_{s=1}^{S}\left[\frac{\exp \left(\beta_{s} X_{i j}\right)}{\sum_{k=1}^{K} \exp \left(\beta_{s} X_{i k}\right)}\right]\left[\frac{\exp \left(\lambda_{s} Z_{i}\right)}{\sum_{s=1}^{S} \exp \left(\lambda_{s} Z_{i}\right)}\right]$ (see Greene and Hensher [40] for details on the LC model).

\section{Methods}

\subsection{Data Collection}

In order to collect data, an online survey was implemented in Korea. We randomly selected a study sample of 1000 casino users from an email list comprising about 20,000 domestic and overseas casino visitors, which was administered by a marketing research company. We also distributed our survey invitations with a uniform resource locator (URL) link to the questionnaire. As a result, 951 respondents participated in our survey procedure. With a series of screening questions, we excluded 382 survey participants reporting that they had no international travel experience using airplanes. Additionally, we dropped 38 respondents who had no interest in in-flight casino facilities. This data screening procedure yielded a total of 531 responses for further analysis.

\subsection{Attributes and Hypotheses}

The successful identification of product attributes constituting the hypothetical in-flight casino and the effective allocation of relevant levels to each attribute are crucial for better understanding respondents' innate preference patterns [30]. A session of focus group interview with casinos (e.g., Kangwon Land and Paradise Group) and airlines (e.g., Asiana Airlines and Korean Airlines) professionals in addition to an extensive review of previous literature [21-28] generated eight different attributes including gaming duration, casino capacity, internal environment, number of games, service quality, comps, instruction, and entrance fee. Once developing these in-flight casino attributes, we allotted two or three different levels to each attribute. More details on in-flight casino attributes and levels as well as research hypotheses regarding each attribute are as follows (see Table 2):

- GAMING DURATION represents the proportion of in-flight casino operation time to total flight duration. This attribute consists of three quantitative levels (i.e., " $30 \%$ of total flight time", " $50 \%$ of total flight time", and "70\% of total flight time"). This study expected a positive coefficient signal because previous studies [22,28] indicated casino users' tastes for a longer period of casino operation.

Hypothesis 1 (H1): GAMING DURATION positively affects in-flight casino users' preferences.

CASINOCAPACITY shows the proportion of in-flight casino seats to total number of passengers. This attribute includes three quantitative levels (i.e., " $10 \%$ of total number of passengers", " $15 \%$ of total number of passengers", and "20\% of total number of passengers"). Based on previous studies [27], we hypothesized a positive coefficient sign due to casino users' preferences for more gaming opportunities.

Hypothesis 2 (H2): CASINO CAPACITY positively affects in-flight casino users' preferences. 
INTERNAL ENVIRONMENT represents overall quality of internal environment in the casinos associated with lightings, decorations, and furniture. This attribute comprises three qualitative levels (i.e., "Acceptable", "Good", and "Excellent"). Earlier servicescape studies [26,28] provided empirical evidence of positive coefficient signals because of customers' strong preferences for better service settings.

Hypothesis 3 (H3): INTERNAL ENVIRONMENT positively affects in-flight casino users' preferences.

NUMBER OF GAMES indicates the number of games available in in-flight casinos. This attribute also involves three quantitative levels (e.g., "3 types", "6 types", and "9 types"). We hypothesized a positive coefficient signal because casino users are likely to prefer more different types of casino games [22].

Hypothesis 4 (H4): NUMBER OF GAMES positively affects in-flight casino users' preferences.

SERVICE QUALITY shows overall quality of in-flight casino dealer services. Three qualitative levels (i.e., "Acceptable", "Good", and "Excellent") were employed for this attribute. This study hypothesized positive coefficient signals because of casino users' tastes for higher quality of dealer services [27].

Hypothesis 5 (H5): SERVICE QUALITY positively affects in-flight casino users' preferences.

- COMPS denotes levels of complimentary items and rebates. This attribute has three qualitative levels (i.e., "Free alcohol", "Free restaurant meals", and "Free hotel rooms"). We hypothesized positive coefficient signs since casino users are likely to reveal their preferences for higher priced complimentary goods [25].

Hypothesis 6 (H6): COMPS positively affect in-flight casino users' preferences.

- INSTRUCTION indicates the availability of instructions on responsible gaming provided by in-flight casino staff prior to entering the casino. This attribute involves two qualitative levels (i.e., "Not available" and "Available"). We hypothesized a negative coefficient sign because casino users are likely to show their distaste for this type of instruction [21,23].

Hypothesis 7 (H7): INSTRUCTION negatively affects in-flight casino users' preferences.

ENTRANCE FEE represents prices for the in-flight casino entrance ticket. This quantitative attribute comprises of three different levels (i.e., “US $\$ 50$ ", “US $\$ 100$ ”, and “US $\$ 150$ ”). Due to the general aversion to higher prices, we anticipated a negative coefficient sign for this attribute [28].

Hypothesis $\mathbf{8}$ (H8): ENTRANCE FEE negatively affects in-flight casino users' preferences. 
Table 2. Attributes and levels.

\begin{tabular}{|c|c|c|c|c|}
\hline Attributes & Description & & Levels & $\begin{array}{c}\text { Hypothesis (Coefficient } \\
\text { Sign) }\end{array}$ \\
\hline GAMING DURATION & $\begin{array}{l}\text { The proportion of the casino } \\
\text { operation time to total flight } \\
\text { duration of the airplane }\end{array}$ & $\begin{array}{l}1 . \\
2 . \\
3\end{array}$ & $\begin{array}{l}30 \% \text { of total flight time }{ }^{1} \\
50 \% \text { of total flight time } \\
70 \% \text { of total flight time }\end{array}$ & $\mathrm{H} 1(+)$ \\
\hline CASINO CAPACITY & $\begin{array}{l}\text { The proportion of the in-flight } \\
\text { casino seats to total number of } \\
\text { passengers }\end{array}$ & $\begin{array}{l}1 . \\
2 . \\
3 .\end{array}$ & $\begin{array}{l}10 \% \text { of total number of passengers } \\
15 \% \text { of total number of passengers } \\
20 \% \text { of total number of passengers }\end{array}$ & $\mathrm{H} 2(+)$ \\
\hline $\begin{array}{l}\text { INTERNAL } \\
\text { ENVIRONMENT }\end{array}$ & $\begin{array}{l}\text { Overall quality of internal } \\
\text { environment in the casinos } \\
\text { associated with lightings, } \\
\text { decorations, and furniture }\end{array}$ & 1 & $\begin{array}{l}\text { Acceptable }{ }^{1} \text { : Basic quality of internal } \\
\text { environment enough to enjoy gaming } \\
\text { Good: Satisfactory quality of internal } \\
\text { environment with somewhat } \\
\text { luxurious furniture, lightings, } \\
\text { and decorations } \\
\text { Excellent: Exceptional quality of } \\
\text { internal environment with very } \\
\text { luxurious furniture, lightings, } \\
\text { and decorations }\end{array}$ & $\mathrm{H} 3(+)$ \\
\hline NUMBER OF GAMES & $\begin{array}{l}\text { The number of games } \\
\text { available in the in-flight } \\
\text { casinos }\end{array}$ & 1. & $\begin{array}{l}3 \text { types }{ }^{1} \text { : Slot machine, baccarat, } \\
\text { and blackjack } \\
6 \text { types: Roulette, poker, and } \\
\text { pachinko as well as slot machine, } \\
\text { baccarat, blackjack } \\
9 \text { types: Bingo, Big Wheel, and } \\
\text { different video poker as well as } \\
\text { roulette, poker, pachinko, slot } \\
\text { machine, baccarat, blackjack }\end{array}$ & $\mathrm{H} 4(+)$ \\
\hline SERVICE QUALITY & $\begin{array}{l}\text { Overall quality of the in-flight } \\
\text { casino dealer services }\end{array}$ & 1 & $\begin{array}{l}\text { Acceptable }{ }^{1} \text { : Basic service quality } \\
\text { through temporarily hiring flight } \\
\text { attendants as casino dealers } \\
\text { Good: Satisfactory service quality } \\
\text { through hiring semi-professional } \\
\text { casino dealers } \\
\text { Excellent: Exceptional service quality } \\
\text { through hiring professional } \\
\text { casino dealers }\end{array}$ & $\mathrm{H} 5(+)$ \\
\hline COMPS & $\begin{array}{l}\text { Levels of complimentary items } \\
\text { and rebates }\end{array}$ & $\begin{array}{l}1 \\
2 \\
3\end{array}$ & $\begin{array}{l}\text { Free alcohol }{ }^{1} \\
\text { Free restaurant meals } \\
\text { Free hotel rooms }\end{array}$ & $\mathrm{H} 6(+)$ \\
\hline INSTRUCTION & $\begin{array}{l}\text { The availability of instructions } \\
\text { on responsible gaming } \\
\text { provided by the in-flight } \\
\text { casino staff prior to entering } \\
\text { the casino }\end{array}$ & $\begin{array}{l}1 \\
2\end{array}$ & $\begin{array}{l}\text { Not available }^{1} \\
\text { Available }\end{array}$ & $\mathrm{H} 7(-)$ \\
\hline ENTRANCE FEE & $\begin{array}{l}\text { Price for the in-flight casino } \\
\text { entrance ticket }\end{array}$ & $\begin{array}{l}1 \\
2 \\
3\end{array}$ & $\begin{array}{l}\text { US } \$ 50^{1} \\
\text { US } \$ 100 \\
\text { US } \$ 150\end{array}$ & H8 (-) \\
\hline
\end{tabular}

${ }^{1}$ reference category.

\subsection{Experimental Design}

A fractional factorial design with main effects was recruited to generate a manageable number of choice comparisons since a full factorial strategy results in respondents' severe cognitive burden. As recommended by Kuhfeld [41], we developed a total of 36 choice alternatives using the SAS macro, which ensured the $D$-optimal efficiency. In order to further lessen possible response fatigue, we employed a block scheme that splits 36 in-flight casino alternatives into six different questionnaire versions. As a result, our respondents encountered only six paired choice combinations. Prior to 
disseminating online questionnaires, our research advisors possessing professional experiences in casino and airplane industries carefully checked all choice alternatives to detect possible unrealistic profiles.

Besides the two choice options (i.e., 'In-flight casino A' and 'In-flight casino B'), we included a non-choice option of 'Not choose either casino' because some consumers forgo their purchase opportunities in actual markets after sincerely comparing different alternatives. This reference option, which is closely associated with the alternative specific constant (hereafter ASC) term, contributes to an improved knowledge on the average effect of respondents' preferences for particular products [42]. An example of 18 paired comparisons presented to our respondents is illustrated in Figure 1.

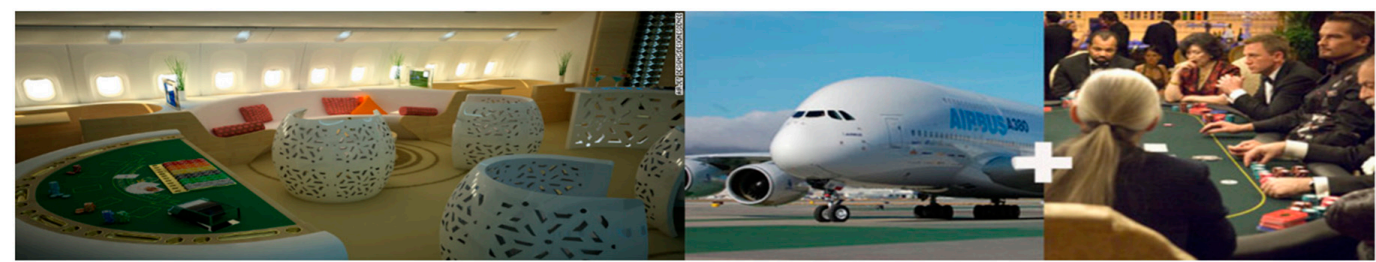

Suppose that you could choose an inflight casino offered by an airplane. Which would you prefer?

\begin{tabular}{|c|c|c|c}
\hline \multicolumn{1}{c|}{ ATTRIBUTES } & IN-FLIGHT CASINO A & IN-FLIGHT CASINO B & NOT CHOOSE EITHER CASINO \\
\hline GAMING DURATION & $70 \%$ of total flight time & $50 \%$ of total flight time & \\
\hline CASINO CAPACITY & $10 \%$ of total number of passengers & $15 \%$ of total number of passengers & \\
\hline INTERNAL ENVIRONMENT & Excellent & Acceptable & \\
\hline NUMBER OF GAMES & 9 types & Excellent & \\
\hline SERVICE QUALITY & Good & Free alcohol & Not available \\
\hline COMPS & Free restaurant meals & US $\$ 50$ & \\
\hline INSTRUCTION & Available & & \\
\hline ENTRANCE FEE & US $\$ 100$ & \\
\hline \hline
\end{tabular}

Figure 1. An example of paired choice sets.

In order to assess the effect of respondents' attitudes toward casino gaming on choice decisions, this study utilized five different measurement items identified from a review of relevant studies [43,44]. Each item employed a five-point Likert response format with values ranging from 1 (strongly disagree) to 5 (strongly agree). The result of an exploratory factor analysis revealed the existence of a single dimension with $72.4 \%$ of variance explained. We included the regression factor score into the indirect utility function to understand the influence of this attitude dimension. Furthermore, several items asking respondents' socio-demographic features were incorporated into the utility function. Table 3 shows the descriptive statistics for respondents' attitudes toward casino gaming activity.

Table 3. Results of the exploratory factor analysis for respondents' attitudes toward casino gaming.

\begin{tabular}{lccc}
\hline \multicolumn{1}{c}{ Measurement Items } & Mean & S.D. & Cronbach's Alpha \\
\hline Casino gaming is important for me & 2.89 & 0.90 & \\
Casino gaming provides important meanings to me & 2.96 & 0.98 & \multirow{2}{*}{0.90} \\
Casino gaming provides a sense of fun & 3.36 & 0.91 & \\
Casino gaming is closely associated with me & 2.99 & 1.03 & \\
Casino gaming is valuable for me & 2.91 & 0.98 & \\
\hline
\end{tabular}

\section{Results}

\subsection{Sample Description}

The majority of our respondents were comprised of males (72.1\%). More than half of respondents $(66.1 \%)$ reported holding a bachelor's degree. The mean age was 37.8 years while the largest portion of 
respondents' age fell within their 30s (43.9\%), followed by 40 s (21.3\%) and 20s (20.3\%). Approximately two out ten respondents (17.1\%) reported their after-tax monthly household income bracket from US\$5000 to US\$6000, followed by the brackets of US\$4000 to 5000 (16.9\%), and US\$2000 to $3000(15.8 \%)$. The vast majority of respondents $(81.7 \%)$ indicated their experience of using Kangwon Land Casino, the only casino facility allowing Koreans to play games, while visiting 2.5 times on average during the past 12 months. On the contrary, exactly two-thirds (66.7\%) stated their visit to overseas casinos with a mean number of 1.9 times during the same period.

\subsection{Random Parameter Logit Models}

Unlike the conditional logit models, the random parameter logit (hereafter RPL) models are immune to the restrictive IIA assumption and advantageous in better understanding respondents' heterogeneous preference patterns [35]. Accordingly, we estimated the RPL models using a MSLE method with the Halton draws 500. We also incorporated a set of interaction terms between different socio-demographic and attitudinal aspects and ASC to be more comprehensively aware of what sources affect respondents' preference heterogeneity. Table 4 demonstrates the estimation results of the RPL model and the RPL model with interaction terms.

Table 4. Estimation results of the random parameter logit (RPL) and the RPL model with interactions.

\begin{tabular}{|c|c|c|c|c|c|}
\hline \multirow{2}{*}{\multicolumn{2}{|c|}{ Attributes and Levels }} & \multicolumn{2}{|c|}{ RPL Model } & \multicolumn{2}{|c|}{ RPL Model with Interactions } \\
\hline & & Coeff. & S.E. & Coeff. & S.E. \\
\hline \multicolumn{6}{|c|}{ Mean Parameters } \\
\hline ASC & & $4.1939 * * *$ & 0.3244 & $3.4921 * *$ & 1.4415 \\
\hline GAMING DURATION & & $0.0039 *$ & 0.0020 & $0.0039 * *$ & 0.0019 \\
\hline CASINO CAPACITY & & 0.0075 & 0.0078 & 0.0077 & 0.0076 \\
\hline INTERNAL & Good & $0.1009 * *$ & 0.0435 & $0.0992 * *$ & 0.0430 \\
\hline ENVIRONMENT & Excellent & $0.1385^{* * *}$ & 0.0443 & $0.1367^{* * *}$ & 0.0436 \\
\hline NUMBER OF GAMES & & $0.0404^{* * *}$ & 0.0133 & $0.0397^{* * *}$ & 0.0128 \\
\hline \multirow{2}{*}{ SERVICE QUALITY } & Good & 0.0070 & 0.0443 & 0.0045 & 0.0438 \\
\hline & Excellent & $0.1102 * *$ & 0.0441 & $0.1088^{* *}$ & 0.0432 \\
\hline \multirow{2}{*}{ COMPS } & Free restaurant meals & -0.0436 & 0.0451 & -0.0429 & 0.0446 \\
\hline & Fee hotel rooms & $0.1120 * *$ & 0.0473 & $0.1092 * *$ & 0.0471 \\
\hline INSTRUCTION & & 0.0269 & 0.0361 & 0.0282 & 0.0356 \\
\hline ENTRANCE FEE & & $-0.0138^{* * *}$ & 0.0010 & $-0.0136^{* * *}$ & 0.0009 \\
\hline ASC & GE & & & $-0.0362^{* *}$ & 0.0170 \\
\hline $\mathrm{ASC} \times \mathrm{C}$ & NDER & & & -0.0039 & 0.3699 \\
\hline $\mathrm{ASC} \times \mathrm{ED}$ & ATION & & & -0.2865 & 0.2397 \\
\hline ASC $\times 1$ & OME & & & 0.0471 & 0.0681 \\
\hline $\mathrm{ASC} \times \mathrm{A}^{\top}$ & TUDES & & & $1.3390^{* * *}$ & 0.1878 \\
\hline \multicolumn{6}{|c|}{ Standard Deviation Parameters } \\
\hline \multicolumn{2}{|c|}{ ASC } & $2.8147^{* * *}$ & 0.2574 & $2.6668^{* * *}$ & 0.2212 \\
\hline \multirow{2}{*}{\multicolumn{2}{|c|}{$\begin{array}{l}\text { GAMING DURATION } \\
\text { CASINO CAPACITY }\end{array}$}} & $0.0132 * * *$ & 0.0037 & $-0.0109 * *$ & 0.0044 \\
\hline & & $0.0392 * *$ & 0.0185 & 0.0217 & 0.0223 \\
\hline \multirow{2}{*}{$\begin{array}{c}\text { INTERNAL } \\
\text { ENVIRONMENT }\end{array}$} & Good & 0.0033 & 0.1143 & 0.0115 & 0.1121 \\
\hline & Excellent & 0.0236 & 0.1480 & 0.0544 & 0.1425 \\
\hline \multicolumn{2}{|l|}{ NUMBER OF GAMES } & 0.0662 & 0.0583 & 0.0544 & 0.0344 \\
\hline \multirow{2}{*}{ SERVICE QUALITY } & Good & $0.2553^{* *}$ & 0.1259 & $0.2641 * *$ & 0.1216 \\
\hline & Excellent & $0.2268 *$ & 0.1310 & 0.2101 & 0.1418 \\
\hline \multirow{2}{*}{ COMPS } & Free restaurant meals & -0.0053 & 0.1360 & -0.0167 & 0.1321 \\
\hline & Fee hotel rooms & $0.4069^{* * *}$ & 0.0914 & $-0.4113^{* * *}$ & 0.0872 \\
\hline INSTRUCTION & & $0.3871^{* * *}$ & 0.0682 & $0.3744^{* * *}$ & 0.0650 \\
\hline \multicolumn{2}{|c|}{ Log Likelihood } & \multicolumn{2}{|c|}{-2666.729} & \multicolumn{2}{|c|}{-2635.286} \\
\hline
\end{tabular}


Among eight different attributes comprising an in-flight casino, six attributes (i.e., GAMING DURATION, INTERNAL ENVIRONMENT, NUMBER OF GAMES, SERVICE QUALITY, COMPS, and ENTRANCE FEE) were at least partially significant in the mean parameters across both models. The ASCs revealed the highest levels of statistical significance with a positive coefficient signal suggesting that our respondents intensely preferred visiting an in-flight casino on average. The negative signs of the ENTRANCE FEE attribute indicate the acceptance of our hypothesis 8 . This result denoted that respondents showed their stronger preferences for in-flight casinos as the entrance ticket prices for the facilities decreased.

The GAMING DURATION attribute was significant with a positive coefficient sign, which is consistent with our hypothesis 1 . This reflects that respondents revealed their preferences for a longer period of casino gaming time. The quantitative attribute of NUMBER OF GAMES was also positively significant, which results in the acceptance of the hypothesis 4 . This result suggests that our respondents were more likely to use an in-flight casino with a higher number of casino games. Unlike our hypothesis 2, the quantitative attribute of CASINO CAPACITY failed to reveal a statistical significance, indicating that respondents were insensitive to the crowdedness of the hypothetical in-flight casinos. Our respondents were in favor of visiting more luxurious casino circumstances compared to the reference level of the acceptable environment, which was substantiated by the positive coefficient sign of the INTERNAL ENVIRONMENT attribute. Accordingly, our hypothesis 3 was fully accepted. The consistent positive signs of both SERVICE QUALITY and COMPS attributes provided supportive evidence of partially accepting our study hypotheses 5 and 6 . These results indicate that the potential in-flight casino users were more interested in the airplane casino facilities with excellent quality of dealer services and the highest level of complimentary items. However, the INSTRUCTION attribute failed to show any statistical significance, which leads to the rejection of our hypothesis 7 . This result suggests that respondents' decisions for choosing an in-flight casino were not affected by the availability of responsible gaming education prior to entering the facility.

The standard deviation parameters in the RPL models demonstrate how respondents' preferences are heterogeneous across different attributes. Among the eleven standard deviation parameters, seven were statistically significant in the RPL model, reflecting that our respondents possessed innate preference heterogeneity for the relevant attributes. Accordingly, we estimated another RPL model with interaction terms to outline what personal features play an important role in determining their preference variability. Among the five different interactions, the mean parameters of the two interaction terms (i.e., ASC $\times$ AGE and ASC $\times$ ATTITUDES) were statistically significant indicating that our respondents with higher age and more positive attitudes toward casino gaming preferred visiting an in-flight casino. This result provided a hint suggesting that the heterogeneous preference in the sample population may be associated with respondents' socio-demographic and attitudinal characteristics.

\subsection{Latent Class Model}

The most important assumption of the LC models is that individuals' preference structures are dependent upon their embedded subgroup membership, which is generally affected by a variety of socio-demographic and emotional characteristics [45]. Due to the unknown nature of the number of embedded segments in our choice data, we estimated a series of the LC models using five different classes. Table 5 shows statistical information resulting from the LC model estimation procedures. We also compared different statistics such as log likelihood, Akaike Information Criterion (hereafter AIC), and Bayesian Information Criterion (hereafter BIC) to detect what LC model with a particular number of subgroups most effectively performed. A set of the likelihood ratio (hereafter LR) tests revealed a meaningful model improvement from the single segment model to two-, three-, and four-class models, implying the presence of preference heterogeneity. Other indicators of AIC and BIC denoted that the optimal number of segments was chosen at two because a smaller statistic of the two criteria normally points to a desirable model [46]. 
Table 5. Statistical information for the number of latent classes.

\begin{tabular}{ccccc}
\hline Number of Classes & Log Likelihood & Number of Parameters & AIC & BIC \\
\hline 1 & -2941.690 & 12 & 5907.385 & 5993.366 \\
2 & -2552.050 & 30 & 5164.101 & 5292.344 \\
3 & -2511.382 & 48 & 5118.765 & 5323.954 \\
4 & -2463.086 & 66 & 5058.172 & 5340.306 \\
5 & -2437.458 & 84 & 5042.916 & 5401.996 \\
\hline
\end{tabular}

AIC: Akaike Information Criterion $=-2(\log \mathrm{L}-\mathrm{K}) / \mathrm{n}$. BIC: Bayesian Information Criterion $=-(2 \log \mathrm{L}-\mathrm{Kl} \operatorname{logn}) / \mathrm{n}$, where $\mathrm{K}$ represents the number of parameters estimated.

The estimation results of the LC model with two-segment solutions are presented in Table 6. The vast majority of respondents $(77.9 \%)$ fell within the boundary of the Class 2 . In particular, the utility function of the Class 2 model showed an identical significance pattern with the mean parameter estimates of the RPL model elaborated above. Accordingly, we skip the detailed explanations regarding the estimation results. Unlike the Class 2 model, the utility function of the Class 1 model exhibited an opposite coefficient signal on the attribute of COMPS. This suggests that respondents in Class 1 were in favor of the highest quality of complimentary items (i.e., free hotel rooms) while they showed a significant aversion to the medium level of comps (i.e., free restaurant meals) compared to the base category of free alcohol offered at in-flight casinos. The segment members also indicated their strong preferences for the responsible gaming instructions prior to entering the casino.

Table 6. Estimation results of the LC model.

\begin{tabular}{|c|c|c|c|c|c|}
\hline \multirow{2}{*}{\multicolumn{2}{|c|}{ Attributes and Levels }} & \multicolumn{2}{|c|}{ Class 1} & \multicolumn{2}{|c|}{ Class 2} \\
\hline & & Coeff. & S.E. & Coeff. & S.E. \\
\hline \multicolumn{6}{|c|}{ Utility Function } \\
\hline \multicolumn{2}{|c|}{ ASC } & $2.7869^{* * *}$ & 0.5098 & $3.7523^{* * *}$ & 0.2817 \\
\hline \multirow{2}{*}{\multicolumn{2}{|c|}{$\begin{array}{l}\text { GAMING DURATION } \\
\text { CASINO CAPACITY }\end{array}$}} & -0.0005 & 0.0047 & $0.0046^{* *}$ & 0.0018 \\
\hline & & -0.0154 & 0.0205 & 0.0075 & 0.0073 \\
\hline \multirow{2}{*}{$\begin{array}{l}\text { INTERNAL } \\
\text { ENVIRONMENT }\end{array}$} & Good & 0.1486 & 0.1295 & $0.0734^{*}$ & 0.0421 \\
\hline & Excellent & -0.1721 & 0.1210 & $0.1435^{* * *}$ & 0.0419 \\
\hline \multicolumn{2}{|c|}{ NUMBER OF GAMES } & 0.0003 & 0.0355 & $0.0345^{* * *}$ & 0.0126 \\
\hline SERVICE & Good & -0.0917 & 0.1164 & 0.0312 & 0.0421 \\
\hline QUALITY & Excellent & $0.2370 * *$ & 0.1084 & $0.1008^{* *}$ & 0.0419 \\
\hline \multirow{2}{*}{ COMPS } & Free restaurant meals & $-0.4236 * * *$ & 0.1253 & -0.0080 & 0.0428 \\
\hline & Fee hotel rooms & $0.1875^{*}$ & 0.1061 & $0.0953^{* *}$ & 0.0424 \\
\hline \multicolumn{2}{|c|}{ INSTRUCTION } & $0.3857^{* * *}$ & 0.0997 & -0.0079 & 0.0293 \\
\hline \multicolumn{2}{|c|}{ ENTRANCE FEE } & $-0.0376^{* * *}$ & 0.0031 & $-0.0080 * * *$ & 0.0008 \\
\hline \multicolumn{6}{|c|}{ Class Membership Function } \\
\hline \multicolumn{2}{|c|}{ AGE } & $0.0343^{* * *}$ & 0.0124 & \multirow{6}{*}{\multicolumn{2}{|c|}{ Fixed parameters }} \\
\hline \multicolumn{2}{|c|}{ GENDER } & -0.0466 & 0.2659 & & \\
\hline \multirow{2}{*}{\multicolumn{2}{|c|}{$\begin{array}{l}\text { EDUCATION } \\
\text { INCOME }\end{array}$}} & 0.1725 & 0.1743 & & \\
\hline & & -0.0429 & 0.0524 & & \\
\hline \multicolumn{2}{|c|}{ ATTITUDES } & $-0.8761^{* * *}$ & 0.1311 & & \\
\hline \multicolumn{2}{|c|}{ Constant } & -1.2753 & 1.0054 & & \\
\hline \multicolumn{2}{|c|}{ Log likelihood } & \multicolumn{4}{|c|}{-2552.050} \\
\hline \multicolumn{2}{|c|}{ Latent class probability } & \multicolumn{2}{|c|}{0.221} & \multicolumn{2}{|c|}{0.779} \\
\hline
\end{tabular}

The class membership function was estimated to identify the sources of respondents' heterogeneous preferences for in-flight casinos. As demonstrated in Table 6, respondents' socio-demographic variable of AGE and their attitudes toward casino gaming served as statistically significant factors in determining the preference differences between the two classes. This result seems to be consistent with the estimation outcomes of the RPL model with interactions. More specifically, our respondents belonging to Class 1 were significantly older and had more negative attitudes toward casino gaming than the Class 2 members. 


\subsection{Model Comparison}

For identifying an optimal model that most successfully addresses our respondents' choice decisions, we compared three different models using a series of indicators including log likelihood, AIC, and BIC. The results of our model comparison are illustrated in Table 7. We implemented an LR test to select a better-performing model from the two nested models (i.e., the RPL model and the RPL model with interactions). As a result, the RPL model with interaction terms was chosen as a better model although this model revealed a disadvantageous aspect regarding model complexity. Furthermore, the two different non-nested models (i.e., the RPL model with interactions and the LC model) were compared through taking the two indicators of AIC and BIC into consideration. The smaller statistics of the two indicators provided reliable evidence that the LC model performed better to elaborate respondents' choice decisions.

Table 7. Model comparison.

\begin{tabular}{lccc}
\hline & RPL Model & RPL Model with Interactions & LC Model \\
\hline Log likelihood & -2666.729 & -2635.286 & -2552.050 \\
Degree of freedom & 23 & 28 & 30 \\
AIC & 5379.459 & 5326.571 & 5164.101 \\
BIC & 5544.257 & 5527.195 & 5292.344 \\
\hline
\end{tabular}

\subsection{Marginal Willingness-to-Pay Values}

We calculated a series of marginal willingness-to-pay (hereafter MWTP) values to weigh each attribute comprising in-flight casinos. The MWTP values or implicit prices are commonly estimated by

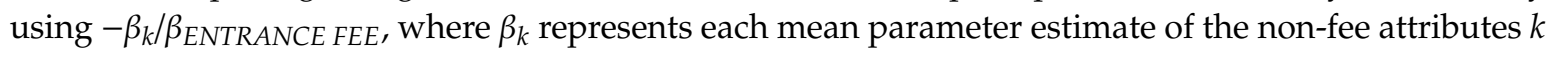
and $\beta_{\text {ENTRANCE FEE }}$ denotes the mean parameter estimate of the ENTRANCE FEE attribute [32]. Table 8 presents different MWTP values resulting from relevant level changes. Since we chose the LC model as the final model, the MWTP values were computed based on the model. The results of the MWTP value calculations indicated that respondents affiliated with Class 2 seemed to show greater preferences for in-flight casinos in that their implicit prices on each attribute were generally higher than the MWTP values of the Class 1 members. Compared to our respondents in Class 1, for example, the Class 2 members were willing to pay US\$6.26 and US\$22.44 more provided that the two attributes of SERVICE QUALITY and INTERNAL ENVIORONMENT were changed from the base level of 'Acceptable' to the highest level of 'Excellent'. The Class 2 members were willing to pay US $\$ 4.29$ more for using an in-flight casino given a marginal change in the attributes of NUMBER OF GAMES. Conversely, casino users in Class 2 did not show any interest in the attribute, which is substantiated by the meager MWTP value of US\$0.01.

Table 8. Results of marginal willingness-to-pay (MWTP) value computations.

\begin{tabular}{lllccc}
\hline \multicolumn{1}{c}{ Attributes } & Level Changes & Class 1 & Class 2 \\
\hline GAMING DURATION & & & & -0.01 & 0.57 \\
CASINO CAPACITY & & $\rightarrow$ & Good & -0.41 & 0.93 \\
\hline INTERNAL & \multirow{2}{*}{ Acceptable } & $\rightarrow$ & Excellent & -4.57 & 9.14 \\
ENVIRONMENT & & & & 0.01 & 4.29 \\
\hline NUMBER OF GAMES & & $\rightarrow$ & Good & -2.44 & 3.88 \\
\hline SERVICE QUALITY & \multirow{2}{*}{ Acceptable } & $\rightarrow$ & Excellent & 6.29 & 12.55 \\
\hline \multirow{2}{*}{ COMPS } & \multirow{2}{*}{ Free alcohol } & $\rightarrow$ & Free restaurant meals & -11.25 & -1.00 \\
& & & Free hotel rooms & 4.98 & 11.87 \\
\hline INSTRUCTION & & Unit: US\$ & & 10.25 & -0.98 \\
\hline
\end{tabular}




\section{Discussions}

\subsection{Study Implications}

The main purpose of this study was to better understand how casino users show their preference heterogeneity regarding the hypothetical in-flight casinos. Using different choice experimental techniques including RPL and LC models, we also attempted to provide useful opportunities for better recognizing how respondents make decisions to visit the novel casino facilities and how much they are willing to pay for several attributes comprising the in-flight gaming space. Although there is no airplane company actually offering this kind of in-flight entertainment, respondents revealed their strong tastes for casino facilities.

The model comparisons showed that our respondents possessed underlying preference diversity regarding the in-flight casino services. This result indicates the importance of market segmentation approach to niche customers. The estimation results of the LC model chosen as the best-performing model for this study revealed two different segments that would likely visit in-flight casinos. The class membership function also denoted that these casino user segments were distinctive in their age and attitudes toward casino gaming behaviors. The LC model estimation results further indicated that almost eight out of ten respondents fell within the Class 2 segment, which was younger and held more positive attitudes toward casinos compared to the Class 1 segment members.

Furthermore, the results of this study have the following important implications. First, Class 2 preferred an excellent internal environment and even was willing to pay more for the relevant attribute. A large percentage of previous studies on casinos have examined the effect of internal environment on several outcome variables, such as customer satisfaction and behavioral intentions [23,25]. Unlike those studies, the current study provided empirical evidence suggesting a significant role of internal environment in the context of in-flight casinos. This result indicates an important managerial implication that airline managers need to offer the highest level of internal environment, which likely enhance customers' levels of gaming satisfaction. An excellent internal environment is also known to improve brand prestige [21]. In other words, if customers perceive that the internal environment of in-flight casinos is great, they are more likely to feel that the brand of the airlines is prestigious. Thus, airline operators need to provide luxury and comfortable internal environment for in-flight casino users.

Second, the Class 2 members are willing to pay more for excellent service quality. The importance of service quality has been constantly confirmed in the casino industry [22,24], suggesting that the quality of dealer services is a key factor in shaping customer satisfaction. This study can be different from most previous studies in that the customer-dealer interactions is a main concern for consumers who are younger and hold more positive attitudes toward casinos. This interpretation can be drawn from the analysis result indicating that they have a greater amount of WTP values for excellent dealer services. Thus, airlines preparing in-flight casinos need to hire professional casino dealers. A wide range of dealer educations using systematic training programs are also needed to offer satisfactory gaming services. More importantly, such training programs are likely to play an important role in improving dealers' job satisfaction [47].

Third, the data analysis results indicated the importance of diversity of casino games as the Class 2 members are willing to pay more for diverse games than the Class 1 members. As we suggested in Table 2, there are many kinds of casino games, such as bingo, big wheel, video poker, roulette, poker, pachinko, slot machine, baccarat, and blackjack. While it is not easy to offer a variety of casino games to customers in the limited space of an aircraft, airlines can increase customers' levels of satisfaction through providing as many types of casino games as possible.

One of several important findings from this study is associated with the attribute of COMPS. The parameter coefficient of the attribute for Class 1 was significantly negative, which suggested that the segment members showed a distaste for free restaurant meals. Since the average meal price is not expensive, our respondents seem to judge that the benefits of free restaurant meals are not great. The results regarding the COMPS attribute showed that the Class 1 and 2 members were in favor 
of free hotel rooms. In particular, the Class 2 members were willing to pay more for those types of comps. This is because the hotel room price is relatively more expensive than the restaurant meal price. Since these rooms are not economically affordable to young users compared to old respondents, Class 2 seems to have a higher WTP value than Class 1 . Thus, it is a more effective strategy for airlines to provide free hotel rooms as comps than free restaurant meals.

Lastly, in terms of the attribute of INSTRUCTION, Class 1 and 2 revealed different preference patterns. The estimation results of the LC model (Table 6) indicated that Class 1 preferred the availability of instructions on responsible gaming, but Class 2 failed to reveal any significant response to the instructional sessions. This result may be attributed to the distinctive nature of the Class 1 segment, which was older and held more negative attitudes toward casinos compared to the Class 2 segment. Thus, airlines preparing in-flight casinos need to develop different instructional opportunities for responsible gaming according to their customers' age and attitudes toward casinos. For instance, if the airline wants to target younger people who have a positive attitude toward casinos, then they should loosen those types of instructions.

\subsection{Study Limitations and Future Studies}

This study provides important theoretical and practical implications as discussed above, but it also has study limitations as follows. First, since this study is based on the airline industry, it is rather difficult to apply the results of this study to other industries. Second, the data collection in this study was conducted in Korea, so future studies may find it useful to collect data from other regions in order to increase external validity. Third, this study conducted choice experiments based on eight attributes of casinos including gaming duration, casino capacity, internal environment, number of games, service quality, comps, instruction, and entrance fee, but it is recommended that future studies reflect more attributes of casinos. Fourth, we did not conduct a non-response check due to the financial restraint. A special caveat is accordingly needed when generalizing our study results to the entire casino user groups.

Author Contributions: Formal analysis, J.H.; Funding acquisition, S.-B.C.; Investigation, S.O.L.; Methodology, J.H.; Writing—original draft, J.H. and S.O.L.; Writing—review \& editing, S.-B.C.

Funding: This research received no external funding.

Conflicts of Interest: The authors declare no conflict of interest.

\section{References}

1. Hwang, J.; Hyun, S.S. First-class airline travellers' perception of luxury goods and its effect on loyalty formation. Curr. Issues Tour. 2015, 20, 497-520. [CrossRef]

2. CS Moniter. Airline Travel: Life in First Class is Getting Cushier. 2011. Available online: http://www.csmonito r.com/USA/2011/1119/Airline-travel-life-in-first-class-is-getting-cushier-but-not-back-in-steerage (accessed on 28 May 2019).

3. The Wall Street Journal. The Long, Slow Death of the First Class Seat. 2012. Available online: http: //www.wsj.com/articles/SB10000872396390444097904577535280680475986 (accessed on 28 May 2019).

4. Cabin Space. Asiana Airlines Inc to Decrease Number of First-Class Seats from Its International Flights. 2015. Available online: http://cabinspace.net/asiana-airlines-inc-to-decrease-number-of-first-class-seats-from-itsinternational-flights/ (accessed on 28 May 2019).

5. The Korea Herald. Budget Carriers Fly over Half of Domestic Travelers in 2014. 2015. Available online: http://www.koreaherald.com/view.php?ud=20150119001227 (accessed on 28 May 2019).

6. Ji, L.; Mazzarella, J. Application of modified nested and dynamic class allocation models for cruise line revenue management. J. Rev. Pricing Manag. 2007, 6, 19-32. [CrossRef]

7. Ng, I.; Yip, N.K. Mechanism design in an integrated approach towards revenue management: The case of Empress Cruise Lines. Serv. Ind. J. 2011, 31, 469-482. [CrossRef]

8. Lee, K.C.; Tsai, W.H.; Yang, C.H.; Lin, Y.Z. An MCDM approach for selecting green aviation fleet program management strategies under multi-resource limitations. J. Air Transp. Manag. 2018, 68, 76-85. [CrossRef] 
9. Pakurár, M.; Haddad, H.; Nagy, J.; Popp, J.; Oláh, J. The Service Quality Dimensions that Affect Customer Satisfaction in the Jordanian Banking Sector. Sustainability 2019, 11, 1113. [CrossRef]

10. Pham, T.Y.; Yeo, G.T. Evaluation of Transshipment Container Terminals' Service Quality in Vietnam: From the Shipping Companies' Perspective. Sustainability 2019, 11, 1503. [CrossRef]

11. Cronin, J.J.; Brady, M.K.; Hult, G.T.M. Assessing the effects of quality, value, and customer satisfaction on consumer behavioral intentions in service environments. J. Retail. 2000, 76, 193-218. [CrossRef]

12. Rodger, K.; Taplin, R.H.; Moore, S.A. Using a randomised experiment to test the causal effect of service quality on visitor satisfaction and loyalty in a remote national park. Tour. Manag. 2015, 50, 172-183. [CrossRef]

13. Taylor, S.A.; Baker, T.L. An assessment of the relationship between service quality and customer satisfaction in the formation of consumers' purchase intentions. J. Retail. 1994, 70, 163-178. [CrossRef]

14. American Gaming Association (2018). State of the States 2018. Available online: https://www.american gaming.org/wp-content/uploads/2018/08/AGA-2018-State-of-the-States-Report_FINAL.pdf (accessed on 28 May 2019).

15. Reuters (2018). Macau Casinos Rake in \$37.6 Billion Gaming Revenue in 2018. Available online: https://www.reuters.com/article/us-macau-gambling-revenues/macau-casinos-rake-in-37-6-billio n-gaming-revenue-in-2018-idUSKCN1OV1BR (accessed on 28 May 2019).

16. Ministry of Culture, Sports and Tourism. Domestic Casino Status. Available online: https://www.google.com/url?sa=t\&rct=j\&q=\&esrc=s\&source=web\&cd=5\&ved=2ahUKEwjv0O-QjZHiA hXfwosBHZGyAKYQFjAEegQIAhAC\&url=https\%3A\%2F\%2Fwww.mcst.go.kr\%2Fservlets\%2Fedupor t $\% 2$ Ffront $\% 2$ Fupload $\% 2 F U$ plDownloadFile $\% 3 F p F i l e N a m e \% 3 D 2018 \% 2 B \% 25 E C \% 25 B 9 \% 25 B 4 \% 25 E C \% 2$ 5A7\%2580\%25EB\%2585\%25B8\%25ED\%2586\%25B5\%25EA\%25B3\%2584\%25282018\%25EB\%2585\%2584\% 2B4\%25EC\%259B\%2594\%2B\%25ED\%2598\%2584\%25EC\%259E\%25AC\%2529.hwp\%26pRealName\%3D1 525412518690.hwp\%26pPath\%3D0408010000\%26pFlag\%3D\&usg=AOvVaw22v-dDq0BWhB9f4fDFp3z_ (accessed on 28 May 2019).

17. Han, H.; Hyun, S.S. Impact of hotel-restaurant image and quality of physical-environment, service, and food on satisfaction and intention. Int. J. Hosp. Manag. 2017, 63, 82-92. [CrossRef]

18. Han, H.; Eom, T.; Chung, H.; Lee, S.; Ryu, H.B.; Kim, W. Passenger Repurchase Behaviours in the Green Cruise Line Context: Exploring the Role of Quality, Image, and Physical Environment. Sustainability 2019, 11, 1985. [CrossRef]

19. Han, H.; Lee, M.J.; Kim, W. Role of shopping quality, hedonic/utilitarian shopping experiences, trust, satisfaction and perceived barriers in triggering customer post-purchase intentions at airports. Int. J. Contemp. Hosp. Manag. 2018, 30, 3059-3082. [CrossRef]

20. Moon, H.; Han, H. Tourist experience quality and loyalty to an island destination: The moderating impact of destination image. J. Travel Tour. Mark. 2019, 36, 43-59. [CrossRef]

21. Hwang, J.; Han, H. A Model of Brand Prestige Formation in the Casino Industry. J. Travel Tour. Mark. 2016, 33, 1106-1123. [CrossRef]

22. Hwang, J.; Han, H.; Choo, S.W. An investigation of the formation of rapport between players and dealers in the casino industry. J. Dest. Mark. Manag. 2016, 5, 97-106. [CrossRef]

23. Jeon, S.M.; Hyun, S.S. Examining the influence of casino attributes on baby boomers' satisfaction and loyalty in the casino industry. Curr. Issues Tour. 2013, 16, 343-368. [CrossRef]

24. Jeon, S.M.; Magnini, V.P.; Kim, I.; Hyun, S.S. Causal relationships between table game players' perceptions of service quality, perceived winning, and game spending: Moderating effects of demographic factors. Int. J. Contemp. Hosp. Manag. 2013, 25, 922-944. [CrossRef]

25. Lam, L.W.; Chan, K.W.; Fong, D.; Lo, F. Does the look mater? The impact of casino servicescape on gaming customer satisfaction, intention to revisit, and desire to stay. Int. J. Hosp. Manag. 2011, 30, 558-567. [CrossRef]

26. Lio, H.L.M.; Rody, R. The emotional impact of casino servicescape. UNLV Gaming Res. Rev. J. 2009, 13, 2.

27. Mayer, K.J.; Johnson, L. A customer-based assessment of casino atmospherics. UNLV Gaming Res. Rev. J. 2003, 7, 2.

28. Wong, I.A.; Fong, V.H.I. Development and validation of the casino service quality scale: CASERV. Int. J. Hosp. Manag. 2012, 31, 209-217. [CrossRef]

29. Shin, S.; Roh, H.S.; Hur, S.H. Characteristics Analysis of Freight Mode Choice Model According to the Introduction of a New Freight Transport System. Sustainability 2019, 11, 1209. [CrossRef] 
30. Hensher, D.A.; Rose, J.M.; Greene, W.H. Applied Choice Analysis; Cambridge University Press: Cambridge, UK, 2015.

31. Louviere, J.; Hensher, D.A.; Swait, J. Stated Choice Methods: Analysis and Applications; Cambridge University Press: Cambridge, UK, 2000.

32. Lyu, S.O.; Lee, Y. How do golf tourists manage golfing constraints? A choice modeling approach. J. Hosp. Tour. Res. 2018, 42, 295-318. [CrossRef]

33. McFadden, D. The measurement of urban travel demand. J. Public Econ. 1974, 3, 303-328. [CrossRef]

34. Ben-Akiva, M.; Lerman, S.R. Discrete Choice Analysis: Theory and Application to Travel Demand; MIT Press: Cambridge, MA, USA, 1985.

35. Train, K.E. Discrete Choice Methods with Simulation; Cambridge University Press: Cambridge, UK, 2003.

36. McFadden, D.; Train, K. Mixed MNL models for discrete response. J. Appl. Econom. 2000, 15, 447-470. [CrossRef]

37. Bhat, C.R. Quasi-random maximum simulated likelihood estimation of the mixed multinomial logit model. Transp. Res. B Meth. 2001, 35, 677-693. [CrossRef]

38. Birol, E.; Karousakis, K.; Koundouri, P. Using a choice experiment to account for preference heterogeneity in wetland attributes: The case of Cheimaditida wetland in Greece. Ecol. Econ. 2006, 60, 145-156. [CrossRef]

39. Morey, E.; Thacher, J.; Breffle, W. Using angler characteristics and attitudinal data to identify environmental preference classes: A latent-class model. Environ. Resour. Econ. 2006, 34, 91-115. [CrossRef]

40. Greene, W.H.; Hensher, D.A. A latent class model for discrete choice analysis: Contrasts with mixed logit. Transp. B Meth. 2003, 37, 681-698. [CrossRef]

41. Kuhfeld, W.F. Marketing Research Methods in SAS: Experimental Design, Efficiency, Coding and Choice Designs; SAS Institute Inc.: Cary, NC, USA, 2005.

42. Bennett, J.; Adamowicz, V. Some fundamentals of environmental choice modeling. In The Choice Modelling Approach to Environmental Valuation; Bennett, J., Blamey, R., Eds.; Edward Elgar: Northampton, MA, USA, 2001; pp. 37-69.

43. Carmichael, B.A.; Peppard, D.M.; Boudreau, F.A. Megaresort on my doorstep: Local resident attitudes toward Foxwoods Casino and casino gambling on nearby Indian reservation land. J. Travel Res. 1996, 34, 9-16. [CrossRef]

44. Lee, C.K.; Back, K.J. Examining structural relationships among perceived impact, benefit, and support for casino development based on 4 year longitudinal data. Tour. Manag. 2006, 27, 466-480. [CrossRef]

45. Boxall, P.C.; Adamowicz, W.L. Understanding heterogeneous preferences in random utility models: A latent class approach. Environ. Resour. Econ. 2002, 23, 421-446. [CrossRef]

46. Cameron, A.C.; Trivedi, P.K. Microeconometrics Using STATA.; STATA Press: College Station, TX, USA, 2010.

47. Back, K.J.; Lee, C.K.; Abbott, J. Internal relationship marketing: Korean casino employees' job satisfaction and organizational commitment. Cornell Hosp. Q. 2011, 52, 111-124. [CrossRef] 